\title{
Bone mineral density in the normal Iranian population: a comparison with American reference data
}

\author{
Gholamhossein Ranjbar Omrani • \\ Seyed Masoom Masoompour • Afshin Hamidi • \\ Heydar Ali Mardanifard • Seyed Morteza Taghavi • \\ Pedram Talezadeh • Bagher Larijani
}

Received: 23 November 2005 / Accepted: 6 July 2006 / Published online: 17 October 2006

(C) International Osteoporosis Foundation and National Osteoporosis Foundation 2006

\begin{abstract}
Summary In order to establish the normative curves for BMD in Iranian individuals, we measured BMDs at the lumbar spine and femoral regions of 760 women and 632 men using dual-energy X-ray absorptiometry. This study provides a baseline normative for Iranian individuals. BMD values of Iranian subjects were generally lower than those of the American population.

Introduction In order to establish the normative curves for BMD in Iranian individuals, we measured BMDs at the lumbar spine and femoral regions. The BMDs at the lumbar spine and femoral neck regions of 760 women and 632 men, which were selected by multi-stage random sampling, were measured using dual-energy X-ray absorptiometry (DXA).

Results The peak bone mass in the males and females at the lumbar spine was reached around the age of $28.5 \pm 1.5$ and $30 \pm 2$ and at the neck of the femur was reached around the age of $24 \pm 1.5$ and $33 \pm 2$. About $16.4 \%$ and $3 \%$ of men aged 50 and older were osteoporotic according to American reference data, respectively, but using Iranian normative data for L2-L4 and the neck of the femur, the corresponding
\end{abstract}

G. R. Omrani $(\bowtie) \cdot$ S. M. Masoompour • A. Hamidi •

S. M. Taghavi $\cdot$ P. Talezadeh

Endocrine and Metabolism Research Center, Nemazee Hospital,

Shiraz University of Medical Sciences,

Shiraz, Iran

e-mail: hormone@sums.ac.ir

H. A. Mardanifard

Department of Statistics, Shiraz University,

Shiraz, Iran

B. Larijani

Endocrinology and Metabolism Research Center,

Tehran University of Medical Sciences,

Tehran, Iran values were only $13.4 \%$ and $2.1 \%$. Using American reference data, the respective values in women aged 50 and older for the same regions were $44.4 \%$ and $12 \%$, whereas according to the Iranian normative data, the corresponding rates were $41.1 \%$ and $10.4 \%$.

Conclusions This study provides a baseline normative for Iranian individuals. Due to the differences in ethnicity, diet, lifestyle, and small body size, BMD values of Iranian subjects were generally lower than those of the American population.

Keywords Bone mineral density · Iranian · Osteoporosis . Normal range

\section{Introduction}

Osteoporosis is an important metabolic bone disease characterized by low bone mineral density (BMD), decreased bone strength and an increased incidence of fragility and fractures. Bone densitometry is considered to be an essential key for the estimation of fracture risk and osteoporosis. The problems concerning the control of loss of bone mass after adulthood, which is a characteristic of osteoporosis, have raised an increasing interest in prophylactic procedures, such as achieving an adequate peak bone mass [1,2], as the bone mass at any time during adulthood represents the ratio between the amount obtained during adulthood and its loss caused by the aging process [3].

About $75 \%$ of the variability in bone strength may be predicted by BMD [4], and therefore the risk of fracture is best determined by measuring BMD values. In clinical practice, an individual measurement of BMD is compared to the reference value followed by the clinical decision for treatment. According to the definition of osteoporosis 
provided by the World Health Organization (WHO), an individual is osteopenic if $-2.5<\mathrm{T}$-Score $<-1$ and osteoporotic if the T-score is $<-2.5$ [5]. Clearly, if inappropriate values of peak bone density and standard deviation were used, the diagnosis of osteoporosis would be over- or understimated [6]. Therefore, using a reference range for a different population introduces a systematic error in the assessment of osteoporosis. BMD is influenced by several factors, the most important of which are age and gender. Another factor that should be taken into account is different normal values of BMD for each geographic area, ethnicity, and body size; thus, it may be better to compare the BMD of each population with the normal value of the same ethnic group. The aim of this study was to measure the BMD of the lumbar spine and proximal femur of a large number of healthy Iranian individuals in order to construct a reference range for the Iranian population and to assess the validity of using a foreign database for diagnosis. Additionally, the data collected were compared to reference data for BMD in the United States. In this study, we examined about 760 female and 632 male healthy individuals aged from 20 to 79 years from different areas in Shiraz. Shiraz is located in southwestern Iran. The present study describes the first attempt to provide a guideline for distribution of normal BMD values in a sample of healthy Iranian individuals.

\section{Subjects and methods}

For the study, 1,392 (760 females and 632 males) healthy Iranian individuals were randomly selected from all regions of Shiraz. All were in the range of 20-79 years old and of Iranian origin. The local ethics committee approved the study, and written informed consent was obtained from each individual. According to the municipality of Shiraz, the city is divided into 88 areas, and even numbers were selected for this study. In each area, homes whose numbers ended in zero were selected, and in each home, one person was selected until the individuals in each group reached 45 persons. For this study, 1,980 individuals were invited to participate, and 1,658 individuals came for assessment. After two recalls, there was no significant difference between the mean age and sex distribution of individuals who came and who did not come. Of the subjects, 322 refused to participate in this study $(16.26 \%)$. All the individuals were evaluated by having a medical history taken and a physical examination performed.

\section{Exclusion criteria}

The individuals not included in the study comprised those with a history of any chronic medical problem, pathologic
Fig. 1 The mean BMD value of the lumbar spine (L2-L4) and the neck of the femur in different age groups in healthy Iranian men and women
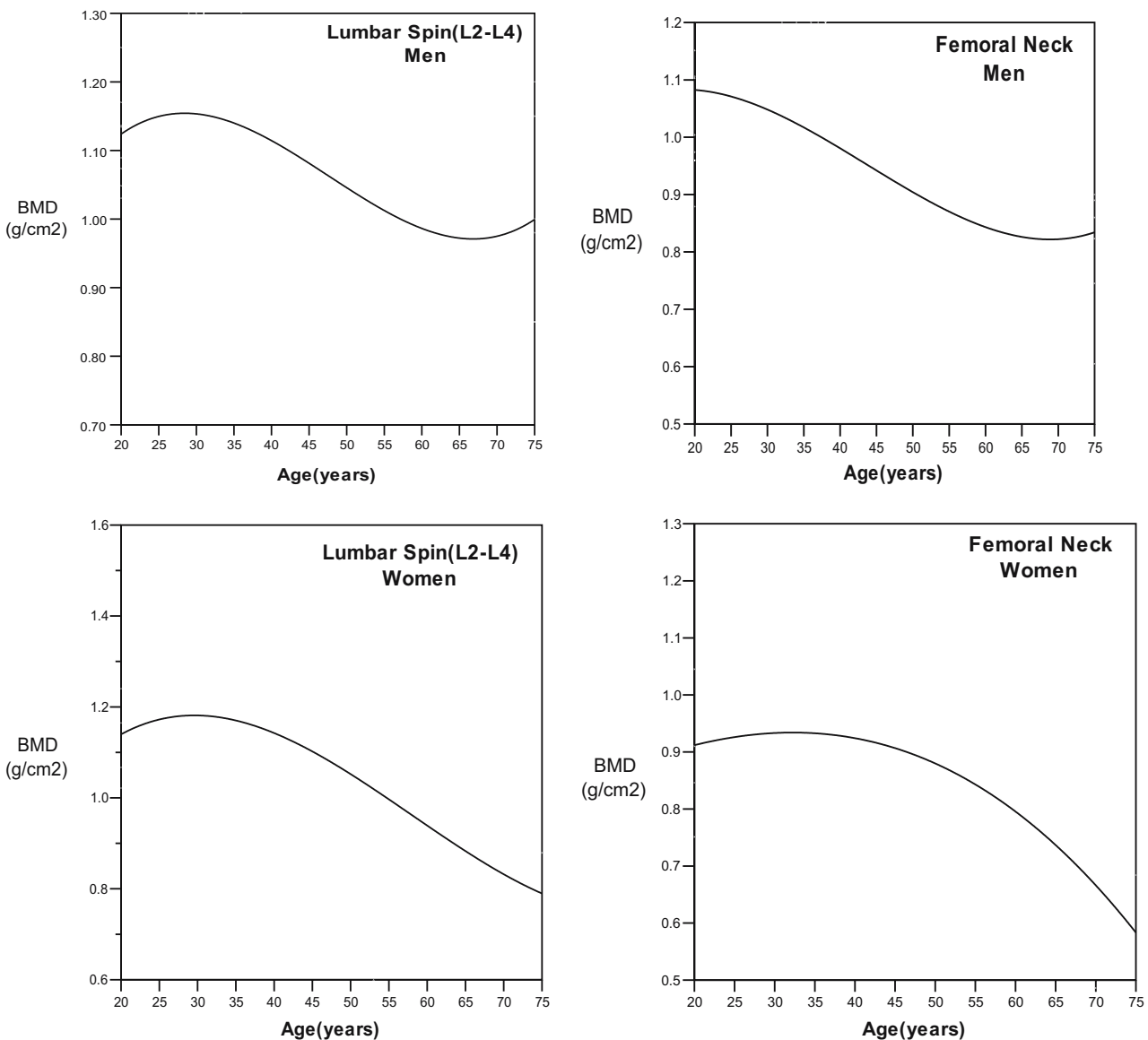
Table 1 The height, weight, and BMI (mean and standard deviation) of normal Iranian men and women

\begin{tabular}{|c|c|c|c|c|c|c|c|c|c|c|c|c|c|c|}
\hline \multirow[b]{3}{*}{ Age } & \multicolumn{7}{|l|}{ Male } & \multicolumn{7}{|c|}{ Female } \\
\hline & \multirow[b]{2}{*}{$\mathrm{n}$} & \multicolumn{2}{|c|}{ Height (cm) } & \multicolumn{2}{|c|}{ Weight (kg) } & \multicolumn{2}{|c|}{ BMI $\left(\mathrm{kg} / \mathrm{m}^{2}\right)$} & \multirow[b]{2}{*}{$\mathrm{n}$} & \multicolumn{2}{|c|}{ Height (cm) } & \multicolumn{2}{|c|}{ Weight (kg) } & \multicolumn{2}{|c|}{ BMI $\left(\mathrm{kg} / \mathrm{m}^{2}\right)$} \\
\hline & & Mean & $\mathrm{SD}$ & Mean & $\mathrm{SD}$ & Mean & $\mathrm{SD}$ & & Mean & SD & Mean & SD & Mean & $\mathrm{SD}$ \\
\hline $20-29$ & 104 & 177.8 & 6.4 & 70.7 & 13.8 & 22.3 & 3.8 & 133 & 163.4 & 5.4 & 58.3 & 10.7 & 21.8 & 3.7 \\
\hline $30-39$ & 131 & 175.6 & 7.2 & 74.1 & 13.2 & 24 & 3.7 & 151 & 162.5 & 5.7 & 65.2 & 10.3 & 24.7 & 3.8 \\
\hline $40-49$ & 137 & 172.1 & 6.8 & 71.4 & 11.8 & 24.1 & 3.8 & 161 & 160.5 & 6 & 67.3 & 12.5 & 26.4 & 4 \\
\hline $50-59$ & 128 & 170.1 & 6.8 & 71.1 & 13.4 & 24.5 & 3.7 & 162 & 156.3 & 6.6 & 66.1 & 13.9 & 27.4 & 4.8 \\
\hline$>60$ & 132 & 169.7 & 6.5 & 69.6 & 11.5 & 24 & 3.2 & 153 & 153.7 & 6.2 & 62.5 & 12.6 & 26.3 & 4.4 \\
\hline
\end{tabular}

fractures, malignancy, chronic use of medications such as anticonvulsants, glucocorticoids, thyroid hormones, vitamin supplements, bisphosphonates and hormone replacement therapy for the postmenopausal women group, which could affect bone metabolism, and also individuals who had undergone gastric surgery, those with any dietary restrictions or special nutritional habits, pregnancy, lactation during the study, a history of premature menopause, and prolonged bed rest. Women weighing more than $100 \mathrm{~kg}$ or less than $40 \mathrm{~kg}$, and men weighing above $110 \mathrm{~kg}$ or below $45 \mathrm{~kg}$, were also excluded.

Bone mineral density

The BMDs of all the subjects were determined at the neck of the left femur and lumbar spine by dual-energy X-ray absorptiometry (DXA) using the fast scan mode (DPX-IQ, Lunar Co., Madison, WI). Quality control procedures were followed in accordance with the manufacturer's instructions. Instrument variation was determined regularly by a daily calibration using a phantom supplied by the manufacturer (the coefficient variation of the phantom was less than $0.5 \%$ ). The in vivo coefficient variation $(\mathrm{CV})$ of the instrument was less than $1.2 \%$ for the lumbar spine and $1.1 \%$ for the femoral neck.

The peak bone mineral density (PBMD) at the spine and neck of the femur regions was calculated using two different methods. In the first method, the cubic regression equation in Fig. 1 was adopted to calculate PBMD, which was equivalent to the highest BMD in each fitting curve. In the second method, the PBMD was calculated using a cross-section of age and the average of the values in subjects 20-29. The PBMD in the first method was greater than that calculated by the second method. The T score was calculated by the PBMD that was obtained by the second method. The same value was used from the American database [7].

\section{Statistical analysis}

The data were analyzed by using SPSS version 11.5 (SPSS Inc., Chicago, IL) and Maple programs. Pearson correlation was used to determine the relationship between BMD with age, weight, height, and body mass index (BMI). According to Levene's test, the variances of the Iranians were different from those of Americans [7]; therefore, for comparing the mean of BMDs between these groups, namely Iranians and Americans, the P-value was calculated from the $\mathrm{Z}$ score test formula.

We used eight regression models to fit the changing curves of BMD at the spine and femoral neck sites according to age and sex groups in Iranians. We observed that the cubic regression had the highest R2 value, suggesting that the cubic regression model had the best goodness of fit.

Table 2 Correlation between age, weight, height, and body mass index (BMI) with BMD in Iranian individuals

\begin{tabular}{|c|c|c|c|c|c|c|c|c|}
\hline & \multicolumn{4}{|l|}{ Male } & \multicolumn{4}{|l|}{ Female } \\
\hline & \multicolumn{2}{|l|}{ L2-L4 } & \multicolumn{2}{|c|}{ Neck of femur } & \multicolumn{2}{|l|}{ L2-L4 } & \multicolumn{2}{|c|}{ Neck of femur } \\
\hline & Age $<50$ & Age $>=50$ & Age $<50$ & Age $>=50$ & Age $<50$ & Age $>=50$ & Age $<50$ & Age $>=50$ \\
\hline Age & $-0.293^{\mathrm{a}}$ & 0.123 & $-0.356^{\mathrm{a}}$ & $-0.189^{\mathrm{a}}$ & $-0.173^{\mathrm{a}}$ & $-0.304^{\mathrm{a}}$ & -0.047 & $-0.419^{\mathrm{a}}$ \\
\hline Weight & $0.318^{\mathrm{a}}$ & $0.293^{\mathrm{a}}$ & $0.389^{\mathrm{a}}$ & $0.385^{\mathrm{a}}$ & 0.043 & $0.503^{\mathrm{a}}$ & $0.237^{\mathrm{a}}$ & $0.577^{\mathrm{a}}$ \\
\hline Height & $0.310^{\mathrm{a}}$ & $0.296^{\mathrm{a}}$ & $0.335^{\mathrm{a}}$ & $0.309^{\mathrm{a}}$ & $0.233^{\mathrm{a}}$ & $0.376^{\mathrm{a}}$ & $0.223^{\mathrm{a}}$ & $0.398^{\mathrm{a}}$ \\
\hline BMI & $0.207^{\mathrm{a}}$ & $0.397^{\mathrm{a}}$ & $0.244^{\mathrm{a}}$ & $0.421^{\mathrm{a}}$ & 0.11 & $0.456^{\mathrm{a}}$ & $0.205^{\mathrm{a}}$ & $0.455^{\mathrm{a}}$ \\
\hline
\end{tabular}

${ }^{\mathrm{a}} \mathrm{P}$ value $<0.01$ 
Table 3 Mean BMD and SD in different age groups and genders in healthy Iranian individuals

\begin{tabular}{|c|c|c|c|c|c|c|c|c|c|c|}
\hline \multirow[b]{3}{*}{ Age } & \multicolumn{5}{|l|}{ Male } & \multicolumn{5}{|c|}{ Female } \\
\hline & \multirow[b]{2}{*}{ No. } & \multicolumn{2}{|l|}{ L2-L4 } & \multicolumn{2}{|c|}{ Neck of femur } & \multirow[b]{2}{*}{ No. } & \multicolumn{2}{|l|}{ L2-L4 } & \multicolumn{2}{|c|}{ Neck of femur } \\
\hline & & Mean & SD & Mean & SD & & Mean & $\mathrm{SD}$ & Mean & SD \\
\hline $20-29$ & 104 & 1.160 & 0.11 & 1.030 & 0.11 & 133 & 1.170 & 0.10 & 0.900 & 0.11 \\
\hline $30-39$ & 131 & 1.110 & 0.12 & 0.960 & 0.11 & 151 & 1.150 & 0.10 & 0.930 & 0.11 \\
\hline $40-49$ & 137 & 1.050 & 0.11 & 0.910 & 0.11 & 161 & 1.130 & 0.13 & 0.920 & 0.11 \\
\hline $50-59$ & 128 & 1.020 & 0.11 & 0.870 & 0.11 & 162 & 0.990 & 0.14 & 0.830 & 0.11 \\
\hline$>60$ & 132 & 1.020 & 0.14 & 0.800 & 0.11 & 153 & 0.880 & 0.16 & 0.730 & 0.11 \\
\hline
\end{tabular}

\section{Results}

After completing a screening questionnaire, which included details of the past medical history and drug therapy, 266 out of 1,658 were excluded; 85 had a history of endocrinological disorders (such as hyperthyroidism, hyperparathyroidism, and diabetes mellitus), 20 had a history of liver dysfunction, 32 had a history of kidney dysfunction, 104 were on drug therapy known to interfere with bone metabolism, and 25 had a history of fracture. The 1,392 individuals ( 760 females, 632 males) were stratified by age and divided into five subgroups for cross-sectional analyses. Mean values of height, weight and BMI, according to age, are given in Table 1.

The peak bone mass in males at the lumbar spine and the neck of the left femur was reached at the age of about $28.5 \pm$ 1.5 and $24 \pm 1.5$ years and was about $1.170 \pm 0.005 \mathrm{~g} / \mathrm{cm}^{2}$ and $1.035 \pm 0.005 \mathrm{~g} / \mathrm{cm}^{2}$, respectively (Fig. 1). An agerelated decrease in bone density began after the age of 30 in males. The average age-related decrease in bone density was about $0.37 \%$ per year at the lumbar spine and the neck of the femur from the age of 30 to 60 , but was followed by a significant increase of about $2 \%$ per year after the age of 60 .

The peak bone mass in females at the lumbar spine and the neck of the left femur was reached at the age of about $30 \pm 2$ and $33 \pm 2$ years and was about $1.195 \pm 0.005 \mathrm{~g} / \mathrm{cm}^{2}$

Table 4 Mean BMD and SD in women based on menopausal status and years since menopause

\begin{tabular}{llllll}
\hline & \multicolumn{2}{l}{ L2-L4 } & & \multicolumn{2}{l}{ Neck of femur } \\
\cline { 2 - 3 } \cline { 6 - 7 } & Mean & SD & & Mean & SD \\
\hline Premenopause & 1.151 & 0.13 & & 0.926 & 0.11 \\
Postmenopause & 0.942 & 0.18 & & 0.786 & 0.13 \\
$\begin{array}{l}\text { Years since menopause } \\
<5\end{array}$ & & & & \\
$5-10$ & 1.034 & 0.20 & & 0.833 & 0.14 \\
$>10$ & 0.975 & 0.17 & & 0.811 & 0.12 \\
& 0.885 & 0.17 & & 0.748 & 0.12 \\
\hline
\end{tabular}

and $0.935 \pm 0.005 \mathrm{~g} / \mathrm{cm}^{2}$, respectively (Fig. 1). In this group, the BMD did not change up to 40 years, after which up to 50 years, the age-related decrease in bone density was about $0.6 \%$ and $0.3 \%$ per year at the lumbar spine and the neck of the femur, respectively. From the age of 50-60, the corresponding age-related decrease in bone density increased to $1 \%$ and $1.4 \%$ per year, and after the age of 60 years the age-related decrease in bone density increased to about $2.2 \%$ per year.

Except for the L2-L4 BMD in females younger than 50 years, there was a statistically significant correlation among the weight, height, and body mass index with BMD of the spine and the neck of the femur in both genders. The foregoing correlation was stronger for weight than height in both sexes, especially after the age of 50 years (Table 2).

\section{Iranian BMD versus American BMD}

Iranian spine and femoral neck BMD values grouped in terms of age (in decades) are shown in Table 3, and BMD of the lumbar spine and femoral neck regions in women stratified into premenopause, postmenopause and years since menopause are shown in Table 4. The comparison between Iranian and American BMDs is displayed in Table 5 .

As shown in Table 4, the BMD of the lumbar spine and femoral neck decline in perimenopausal women, and this decline has an inverse correlation with years since menopause $(r=-0.342, P=0.000$ and $r=-0.324, P=0.000$, respectively). When the correlations were adjusted for age, the significant inverse correlation between the lumbar spine and years since menopause was still present $(r=-0.166$, $P=0.025$ ), but the correlation between the femoral neck and years since menopause was no longer significant $(r=-0.050$, $P=0.5$ ).

As for the spine BMD, in females aged 20-29, 30-39, $40-49,50-59$ and $>60$, the spine BMDs of the Iranians were about $7 \%, 7.6 \%, 5.9 \%, 12 \%$ and $11 \%$ lower than those of the Americans, respectively (Table 5).

In regard to the females in the age groups 20-29, 30-39, $40-49,50-59$ and $>60$, the neck of the femur BMDs of the 
Table 5 Comparison among the mean BMD, height, and weight in Iranians versus Americans (Iranian mean minus Americans)

\begin{tabular}{|c|c|c|c|c|c|c|c|c|}
\hline \multirow[b]{3}{*}{ Age } & \multicolumn{4}{|l|}{ Male } & \multicolumn{4}{|l|}{ Female } \\
\hline & \multicolumn{2}{|l|}{ L2-L4 } & \multicolumn{2}{|c|}{ Neck of femur } & \multicolumn{2}{|l|}{ L2-L4 } & \multicolumn{2}{|c|}{ Neck of femur } \\
\hline & Difference & $P$ value & Difference & $P$ value & Difference & $P$ value & Difference & $P$ value \\
\hline $20-29$ & -0.095 & 0.000 & -0.077 & 0.000 & -0.072 & 0.008 & -0.112 & 0.000 \\
\hline $30-39$ & -0.105 & 0.000 & -0.078 & 0.000 & -0.076 & 0.000 & -0.056 & 0.001 \\
\hline $40-49$ & -0.124 & 0.000 & -0.091 & 0.000 & -0.059 & 0.000 & -0.022 & 0.047 \\
\hline $50-59$ & -0.141 & 0.000 & -0.115 & 0.000 & -0.123 & 0.000 & -0.053 & 0.000 \\
\hline$>60$ & -0.161 & 0.000 & -0.120 & 0.000 & -0.116 & 0.000 & -0.051 & 0.000 \\
\hline
\end{tabular}

Iranians were about $11.2 \%, 5.6 \%, 2.2 \%, 5.3 \%$ and $5.1 \%$ lower than those of the Americans, respectively (Table 5).

Overall, the height of Iranian females after the age of 40 was significantly lower than that of Americans. Except for the weight of those 30-49, which was higher than that of Americans, the weight of our females was lower than that of Americans, but the differences were not statistically significant.

In the male group, the spine BMDs of healthy Iranians in the age groups 20-29, 30-39, 40-49, 50-59 and >60 were about $7.5 \%, 8.6 \%, 10.5 \%, 12.1 \%$, and $13.6 \%$ lower than those of Americans, respectively. Moreover, for the neck of the femur, the values of Iranian BMDs according to the aforementioned age groups were $6.9 \%, 7.5 \%, 9 \%, 11.7 \%$, and $13 \%$ lower than those of Americans, respectively (Table 5).

The prevalence of osteoporosis and osteopenia

This report provides lumbar spine and femur BMD normative values for a large group of Iranian females and males, excluding those with excessive weight, disorders and medications that are known to affect bone metabolism. T-scores were calculated using subjects between the ages of 20 and 29 years as the young normal population. More Iranians were defined as osteoporotic and osteopenic using the American reference data as opposed to the Iranian ones obtained from the present study (Table 6). About 16.4\% and $3 \%$ of the men aged 50 and older were osteoporotic using American reference data, but only $13.4 \%$ and $2.1 \%$ were osteoporotic using the Iranian normative data in the L2-L4 and neck of the femur regions, respectively. According to American reference values, $44.4 \%$ and $12 \%$ of women aged 50 and older were osteoporotic for the above-mentioned sites, respectively, whereas $41.1 \%$ and $10.4 \%$ were osteoporotic based on the Iranian normative data.

\section{Discussion}

This report provides spine and femur normative values for a large group of randomly selected healthy Iranian females and males. The objectives of this study were to determine the peak bone mass and normal BMD of the Iranian population and to determine whether their BMD values were substantially different from those of Americans to establish separate Iranian reference data.

These values were compared with recently reported American reference data for the female spine and femur BMD [7]. The age-related changes in BMD of our population generally mirrored the pattern described for American men and women [7-13], although the mean BMD values among the Iranians were generally lower. In the female group, the spine BMDs were lower than American values. The greater decline of spine bone density with age in our Iranian cohort could be due to factors pertaining to nutrition or lifestyle, body habitus, biological factors or to different secular changes between the Iranian and American populations. Body habitus could explain the

Table 6 Prevalence of osteopenia and osteoprosis using American and Iranian reference data in adults aged 50 and older

\begin{tabular}{|c|c|c|c|c|c|c|c|}
\hline & & \multicolumn{2}{|l|}{ Normal } & \multicolumn{2}{|l|}{ Osteopenia } & \multicolumn{2}{|c|}{ Osteoprosis } \\
\hline & & American & Iran & American & Iran & American & Iran \\
\hline \multirow[t]{2}{*}{ Neck of femur } & $\mathrm{F}$ & $24.7 \%$ & $43.1 \%$ & $63.2 \%$ & $46.5 \%$ & $12 \%$ & $10.4 \%$ \\
\hline & $\mathrm{M}$ & $47.3 \%$ & $72.2 \%$ & $49.8 \%$ & $25.7 \%$ & $3 \%$ & $2.1 \%$ \\
\hline \multirow[t]{2}{*}{ L2-L4 } & $\mathrm{F}$ & $18.5 \%$ & $28.3 \%$ & $37 \%$ & $30.6 \%$ & $44.4 \%$ & $41.1 \%$ \\
\hline & $\mathrm{M}$ & $32.8 \%$ & $42.9 \%$ & $50.8 \%$ & $43.7 \%$ & $16.4 \%$ & $13.4 \%$ \\
\hline
\end{tabular}


greater apparent decrease in bone density with aging in Iranians than Americans since thinness has been shown to be a predictor of more rapid bone loss.

At the neck of the femur, the BMDs of the healthy Iranian women were lower than those of Americans females.

In men, the BMDs for the spine and femoral neck were lower than American values throughout the age range of 20-70 years.

Pearson correlation showed that weight was a significant predictor of female spine and femur BMD values for both the premenopausal and postmenopausal decades. Many other studies have shown the effect of body weight on BMDs [7, 8, 14-23]. Increased body weight has been demonstrated to protect against bone loss, perhaps through the production of estradiol in fat tissue [14]. The effect of height on BMD was generally less than that of weight. The body mass index revealed a pattern similar to weight in predicting BMD in females. The BMD showed a significant correlation with weight, height, and body mass index in males. Again, the effect of height on BMD was less than weight.

Iranian BMD data were examined with regard to the prevalence of osteoporosis and osteopenia. We emphasize, however, that this was a cross-sectional study with no data specifically related to fracture risk. Reference data should include healthy young adults, as well as older individuals, in order to demonstrate peak BMD and accurately determine the prevalence of osteoporosis and osteopenia [24]. An expert committee of WHO recently proposed the diagnostic criteria for a clinical definition of osteoporosis and osteopenia [25]. Although WHO guidelines have been established for Caucasian women, we examined their possible application to Iranian females. Similarly, WHO guidelines have been used by other researchers to define osteoporosis and osteopenia in men, although they have not been specifically confirmed for men [26, 27]. We compared the percentage of osteoporotic and osteopenic individuals, using the Iranian and then the American reference values. Peak BMD and standard deviation are two determining parameters in the calculation of T-score. The standard deviation of BMD values for both the spine and femoral neck in men is similar in the Iranian cohort to that observed in American databases. The standard deviation of BMD values for both the spine and femoral neck in women is smaller in the Iranian cohort than that observed in American databases. When the BMD of a subject and the standard deviation of the peak BMD remain constant, the peak BMD increases with a decreased T-score, which indicates that there is a low probability of diagnosing a subject with osteoporosis. As expected with a lower peak $\mathrm{BMD}$, the prevalence of osteoporosis is higher when using an American database vs. an Iranian database.
There were several limitations in this study. The data collected were cross-sectional in nature and thus provide a survey of current BMD values by age and only an approximation of actual mean BMD changes through time. Also, all of the subjects are from a single city in Iran and may not be representative of the entire Iranian population. The reasons for the differences between the normative database in Iranian and American populations are unknown, and the implications of these observations cannot be appreciated until the relationship between bone density and fracture risk in an Iranian population is known.

\section{References}

1. Anderson JJB, Henderson RC (1991) Dietary factors in the development of peak bone mass. In: Burckhardt P, Heaney RP (eds) Nutritional aspects of osteoporosis. Raven Press, New York, pp 3-19

2. Bonjour JP, Theintz G, Law F, Slosman D, Rizzoli P (1994) Peak bone mass. Osteoporos Int 4(suppl 1):7-13

3. Johnston CC, Slemenda CW (1991) The relative importance of nutrition compared to the genetic factors in the development of bone mass. In: Burckhardt P, Heaney RP (eds) Nutritional aspects of osteoporosis. Raven Press, New York, pp 21-25

4. Melton LJ, Chao EYS, Lane J (1988) Biomechanical aspect of fractures. In: Melton LJ, Riggs BL (eds) Osteoporosis. Raven Press, New York, pp 111-131

5. Kanis JA (1994) Assesment of fracture risk and its application to screening for postmenopausal osteoporosis: synopsis of a WHO report. Osteoporos Int 4:368-438

6. Molyvda-Athanasopoulou E, Sioundas A, Hatziioannou K (2000) Dual energy X-ray absorptiometry reference data for Greek population. The impact on diagnosis of using various normal ranges for comparison. Eur J Radiol 36(1):36-40

7. Mazess RB, Barden HS (1999) Bone density of the spine and femur in adult white females. Calcif Tissue Int 65:91-99

8. Mazess RB, Barden HS, Drinka PJ, Bauwens SF, Orwoll ESD, Bell NH (1990) Influence of age and body weight on spine and femur bone mineral density in US white men. J Bone Miner Res 6:645-652

9. Kroger H, Heikkinen J, Laitinen K, Kotaniemi A (1992) Dualenergy X-ray absorptiometry in normal women: a cross-sectional study of 717 Finnish volunteers. Osteoporos Int 2:135-140

10. Karlsson MK, Gardsell P, Johnell O, Nilsson BE, Akesson K, Obrant KJ (1993) Bone mineral normative data in Malm6, Sweden: comparison with reference data and hip fracture incidence in other ethnic groups. Acta Orthop Scand 64:168-172

11. Burger H, van Daele PLA, Algra D, van den Ouweland FA, Grobbee DE, Hofman A et al (1994) The association between age and bone mineral density in men and women aged 55 years and over: the Rotterdam Study. Bone Miner 25:1-13

12. Truscott JG, Simpson D, Fordham NJ (1997) A suggested methodology for the construction of national bone densitometry reference ranges: 1,372 Caucasian women form four UK sites. Br J Radiol 70:1245-1251

13. Mazess RB, Barden HS, Jonhston C, Dawson-Hughes B, Baran D, Powell $M$ et al (1987) Spine and femur density using dualphoton absorptiometry in normal US white women. Bone Miner 2:211-219

14. Ross PD, He Y-F, Yates AJ, Coupland C, Ravn R, McClung M et al (1996) Body size accounts for most differences in bone density 
between Asian and Caucasian women. Calcif Tissue Int 59:339343

15. Bhudhikanok GS, Wang M-C, Eckert K, Matkin C, Marcus R, Bachrach LK (1996) Differences in bone mineral in young Asian and Caucasian Americans may reflect differences in bone size. J Bone Miner Res 11:1545-1556

16. Davis JW, Ross PD, Wasnich RD (1995) Relation of height and weight to the regional variations in bone mass among JapaneseAmerican men and women. Osteoporos Int 5:234-238

17. Edlestein SL, Barrett-Connor E (1993) Relation between body size and bone mineral density in elderly men and women. Am J Epidemiol 138:160-169

18. Harris SS, Dawson-Hughes B (1996) Weight, body composition, and bone density in postmenopausal women. Calcif Tissue Int 59:428-432

19. Ortolani S, Trevisan C, Bianchi ML, Gandolini G, Cherubim R, Polli EE (1993) Influence of body parameters on female peak bone mass and bone loss. Osteoporos Int 3(Suppl 1):S61-S66

20. Tobias JH, Cook DG, Chambers TJ, Dalzel N (1994) A comparison of bone mineral density between Caucasian, Asian and AfroCaribbean women. Clin Sci 87:587-591
21. Felson DT, Zhang Y, Hannan MT, Anderson JJ (1993) Effects of weight and body mass index on bone mineral density in men and women: the Framingham Study. J Bone Miner Res 8:567-573

22. Dawson-Hughes B, Shipp C, Sadowski L, Dallal G (1987) Bone density of the radius, spine, and hip in relation to percent of ideal body weight in postmenopausal women. Calcif Tissue Int 40:3104

23. El-Desouki M (1995) Bone mineral density of the spine and femur in the normal Saudi population. Saudi Med J 16:30-35

24. Looker AC, Johnston CC Jr, Wahner HW, Dunn WL, Calvo MS, Harris TB et al (1995) Prevalence of low femoral bone density in older US women from HNANES III. J Bone Miner Res 10:796-802

25. World Health Organization (1994) Assessment of fracture risk and its application to screening for postmenopausal osteoporosis. Technical Report Series 843. Geneva: WHO

26. Eastell R, Boyle IT, Compston J, Cooper C, Fogelman I, Francis RM et al (1998) Management of male osteoporosis: report of the UK Consensus Group. Q J Med 91:71-92

27. Bilezikian JP (1999) Osteoporosos in men. J Clin Endocrinol Metab 84:343-344 